\title{
Standardization of Adhatoda vasica Nees Market Preparations by RP-HPLC Method
}

\author{
B. K. Sajeeb ${ }^{1}$, Uttom Kumar ${ }^{1}$, Md. Shahadat Hossain ${ }^{1}$ and Sitesh C. Bachar ${ }^{2}$ \\ ${ }^{1}$ Department of Pharmaceutical Technology, Faculty of Pharmacy, University of Dhaka, Dhaka-1000, \\ Bangladesh \\ ${ }^{2}$ Department of Pharmacy, Faculty of Pharmacy, University of Dhaka, Dhaka-1000, Bangladesh
}

(Received: April 17, 2016; Accepted: June 04, 2016; Published (web): June 20, 2016

\begin{abstract}
In recent times, quality control of herbal and traditional medicines with modern scientific techniques and knowledge are of great concern. The present study reveals a simple and improved reversed phase HPLC method for qualitative analyses of Adhatoda vasica Nees market preparations via quantitation of its major metabolite, vasicine as a marker compound. Three market preparations, each of four different herbal and traditional manufacturers, were analyzed. The market preparations were extracted with chloroform and the residue obtained from extraction of each market preparation was analyzed for quantitation of vasicine by RP-HPLC method with ODS column using a mixture of water and methanol (60:40) as mobile phase at a flow rate of $0.5 \mathrm{ml} / \mathrm{min}$. The estimated quantities of vasicine compared to reference standard for marketed products of four different manufacturers were found to be $1.502 \pm 0.064 \mathrm{~g}, 1.590 \pm 0.081 \mathrm{~g}, 1.761 \pm 0.061 \mathrm{~g}$ and $1.627 \pm 0.082 \mathrm{~g}$, respectively per $100 \mathrm{ml}$ of preparation.
\end{abstract}

Key words: Standardization, Quality control, Adhatoda vasica Nees, Vasicine, RP-HPLC

\section{INTRODUCTION}

Plants have been used in many countries for the healing and diseases preventing properties for thousands of years. ${ }^{1}$ From the beginning of human civilization, the plant based treatments were familiar to people by different systems such as Ayurveda, Siddha, Unani, Yoga, Naturopathy, Homoeopathy and many more. ${ }^{2}$ These systems are playing important role in providing health care to large section of population, especially in developing countries. $^{2}$ About $80 \%$ of world population rely chiefly on traditional medicines for their primary health care needs. ${ }^{3}$ Plant based medicines provide first line and basic health services in remote areas where people have been living in poor health care services. ${ }^{4}$ In the recent time, Adhatoda vasica Nees (Family: Acanthaceae) commonly named as basak

Correspondence to: Sitesh C. Bachar

Email: scbachar63@gmail.com

Dhaka Univ. J. Parm. Sci. 15(1): 57-62, 2016 (June) has been used the Indian subcontinent for its prominent bronchodilatory activities. ${ }^{5}$ The uses of $A$. vasica are growing fast in spite of modern $\mathrm{H}-1$ receptor blockers to the world's people due to its less toxic effects and low cost. Beside this, $A$. vasica has been used for multitude of disorders including bronchitis, leprosy, heart troubles, thirst, asthma, fever, vomiting, loss of memory, leucoderma, jaundice, tumors, mouth troubles, sore-eye, fever and gonorrhea. ${ }^{6}$ Investigation showed that beside many more additional components, $A$. vasica leaves contain vasicine and vasicinone (pyrroloquinazoline alkaloids) which are responsible for bronchodilatory activities. ${ }^{7}$ Vasicine is an optically active component in normal environment and get racemized during extraction. ${ }^{8}$

Now-a-days, the quality of herbal and traditional medicines is a raising concern due to the growing demand of traditional systems of medicines. According to the guideline published by the WHO, various macroscopic, microscopic, spectrophoto- 
metric (UV, FTIR, LCMS/MS, LC-NMR, GC-MS) and chromatographic methods (TLC, HPLC, HPTLC, HPLC-MS, HPLC-NMR) are employed for qualitative analyses of A. vasica preparations. ${ }^{9,10}$ Most of the macroscopic (organoleptic properties, moisture content, total ash determination and particle size), microscopic analyses (microbial load), assessment of other toxic materials (pesticide residues, heavy metal analysis and aflatoxins) and $p \mathrm{H}$ determination only fulfill the initial prerequisite of the preparations but not the final quality of the preparations like presence and quantity of active metabolites. ${ }^{11}$ Thus, the developed countries are maintaining the spectrophotometric and chromatographic methods for quality control and standardization of traditional and herbal medicines besides macroscopic and microscopic analyses. ${ }^{12}$ In the present study, an attempt has been taken to standardize the $A$. vasica market preparations via quantitation of its major metabolite vasicine by a simple, precise and cost effective RP-HPLC method.

\section{MATERIALS AND METHODS}

Market samples. Most of our local herbal and traditional manufacturers have started marketing of A. vasica preparation under various trade names. A total of twelve samples from four different manufacturers (three samples of each company) were purchased from local market ensuring that their batch numbers were not similar to each other. The preparations were stored at cool and dark place until use.

Chemicals and instruments. The analytical grade solvents and reagents were used without further purification. HPLC grade methanol (Sigma Aldrich, Germany) and water purified by Millipore system were used for the analysis. RP-HPLC (Shimadzu, Japan) equipped with a manual injector, a vacuum degasser, a multiple-wavelengths UV/Visible detector (Shimadzu SPD 20A, Japan) and an ODS column (Luna $\mathrm{C}_{18} 100 \AA$, 250x4.6 mm I.D., $5.00 \pm 0.30 \mu \mathrm{m}$ particle size) were used for the chromatographic analyses. Reference standard of vasicine (Potency 100\%, Article no. 89821, Batch no. 3784, Report no. 10543241, Germany) was supplied as generous gift by Square Herbal and Neutraceuticals Limited, Pabna, Bangladesh.

\section{Standardization of market preparations}

Preparation of standard solution. The standard stock solution of $640 \mu \mathrm{g} / \mathrm{ml}$ was prepared by dissolving reference standard vasicine in HPLC grade methanol with occasional shaking and sonication. The standard solutions with the concentration of $320 \mu \mathrm{g} / \mathrm{ml}, 160 \mu \mathrm{g} / \mathrm{ml}, 80 \mu \mathrm{g} / \mathrm{ml}, 40$ $\mu \mathrm{g} / \mathrm{ml}$, and $20 \mu \mathrm{g} / \mathrm{ml}$ were then prepared by dilution of stock solution with methanol. All the solutions were filtrated separately through $0.45 \mu \mathrm{m}$ disc filter and preserved at below $4{ }^{\circ} \mathrm{C} .{ }^{13}$

Preparation of market samples. A total of twelve market preparations from four different companies were collected and each product contained $100 \mathrm{ml}$ of liquid preparation. For each sample, about $10 \mathrm{ml}$ of market preparation was taken and shaken with $30 \mathrm{ml}$ of methanol (95\%) for about 10 mins and then treated with aqueous solution of citric acid (5\%). The solution was extracted with chloroform at a ratio of 2:1 (chloroform:solution) for three times and the aqueous layer was collected. The combined collected aqueous layer was filtered and then basified with ammonia solution (25\%) to $\mathrm{pH}$ 9.5 and further extracted with chloroform at ratio of 2:1 (chloroform:solution) for three times. The organic layer was collected, combined and dried at reduced pressure to get yellowish residue. Finally, an appropriate quantity of residue was dissolved in HPLC grade methanol with sonication to prepare sample solution with the concentration of $150 \mu \mathrm{g} / \mathrm{ml}$ and then filtered through $0.45 \mu \mathrm{m}$ disk filter. All the samples were preserved at air tight vial bellow 4 ${ }^{\circ} \mathrm{C} .{ }^{13}$

Chromatographic conditions. The quantity of vasicine in sample solution was estimated by using reversed phase HPLC equipped with $\mathrm{C}_{18}$ column. The isocratic elution was carried out with a binary solvent system of water and methanol (60:40) as mobile phase at a flow rate of $0.5 \mathrm{ml} / \mathrm{min}$ maintained at $19{ }^{\circ} \mathrm{C}$ temperature and $27 \%$ relative humidity. The 
sample injection volume was $20 \mu \mathrm{l}$ and the analyses were monitored with the UV-Vis detector at 298 nm. ${ }^{13,14}$

Quantitation of vasicine in market samples. The concentrations of vasicine in market samples were determined using the calibration curve for reference standard. The standard solutions of different concentrations were analyzed through RPHPLC method and peak areas were recorded. A calibration curve was prepared by using peak areas versus concentrations of standard solutions. Sample solutions $(150 \mu \mathrm{g} / \mathrm{ml})$ were then analyzed with the RP-HPLC method maintaining similar chromatographic conditions and the peak areas were recorded at defined retention time and vasicine concentrations were determined using linear regression equation of the calibration curve. All determinations were conducted in triplicate.

\section{RESULTS AND DISCUSSION}

The quantitation of vasicine in market samples were carried out by RP-HPLC method. The retention time for reference standard vasicine was observed at $4.792 \mathrm{~min}$ (Figure 1). The linear regression equation for the calibration curve was $\mathrm{Y}=25533 \mathrm{X}+11560$ ( $\mathrm{X}=$ concentration and $\mathrm{Y}=$ peak area) with the correlation coefficient $\left(\mathrm{R}^{2}\right)$ of 0.998 (Figure 2, Table 1).

Table 1. Peak areas of RP-HPLC chromatogram for various concentrations of reference standard of vasicine.

\begin{tabular}{ccc}
\hline No. & $\begin{array}{c}\text { Concentration } \\
(\mu \mathrm{g} / \mathrm{ml})\end{array}$ & Peak area \\
\hline 1 & 20 & 520064 \\
2 & 40 & 990128 \\
3 & 80 & 2097316 \\
4 & 160 & 4255907 \\
5 & 320 & 8791634 \\
6 & 640 & 16210732 \\
\hline
\end{tabular}

Table 2. Estimation of vasicine concentration in market sample solutions (150 $\mu \mathrm{g} / \mathrm{ml})$.

\begin{tabular}{lcccc}
\hline Sample & Batch & $\begin{array}{c}\text { Peak area } \\
(\text { average })\end{array}$ & $\begin{array}{c}\text { Vasicine concentration } \\
(\mu \mathrm{g} / \mathrm{ml})\end{array}$ & $\begin{array}{c}\text { Average concentration } \\
(\mu \mathrm{g} / \mathrm{ml}) \pm \text { S.D. }\end{array}$ \\
\hline A & 1 & 627813 & 22.655 & $23.667 \pm 0.849$ \\
& 2 & 682101 & 24.732 & \\
B & 3 & 652914 & 23.615 & $30.724 \pm 1.088$ \\
& 1 & 798801 & 29.197 & \\
& 2 & 862955 & 31.652 & $33.390 \pm 0.723$ \\
C & 3 & 854331 & 31.322 & \\
& 1 & 881722 & 32.370 & $27.769 \pm 1.152$ \\
& 2 & 923303 & 33.961 & \\
\hline & 3 & 920127 & 33.839 & \\
\hline
\end{tabular}

The sample solutions $(150 \mu \mathrm{g} / \mathrm{ml})$ of all batches were analyzed and chromatograms showed different peak areas with the retention time at $4.450 \mathrm{~min}$, $4.767 \mathrm{~min}, 4.833 \mathrm{~min}$ and $4.542 \mathrm{~min}$ for samples A, $\mathrm{B}, \mathrm{C}$ and D, respectively (Figure $3 \mathrm{~A}-\mathrm{D}$ ). The average concentrations of vasicine in each sample solution of four different manufacturers were found to be $23.667 \pm 0.849 \mu \mathrm{g} / \mathrm{ml}, 30.724 \pm 1.088 \mu \mathrm{g} / \mathrm{ml}$, $33.390 \pm 0.723 \mu \mathrm{g} / \mathrm{ml}$ and $27.769 \pm 1.152 \mu \mathrm{g} / \mathrm{ml}$ (Table 2). The quantities of vasicine in market preparations of four different manufacturers were estimated as $1.502 \pm 0.064 \mathrm{~g}, 1.590 \pm 0.081 \mathrm{~g}, 1.761 \pm 0.061 \mathrm{~g}$ and 
$1.627 \pm 0.082 \mathrm{~g}$ per $100 \mathrm{ml}$ preparations (Table 3 ). Standardization of $A$. vasica market preparations were accomplished through quantitative analyses of major metabolite vasicine. The results showed that market preparations contained significant quantity of vasicine when compared to reference standard. The method has the advantages of being simple, precise, less time consuming and more convenient especially for routine analyses, and may be used for evaluating the quality of herbal and traditional medicines beside regular macroscopic and microscopic analyses.

Table 3. Estimation of vasicine in market preparations.

\begin{tabular}{|c|c|c|c|c|c|c|}
\hline Sample & Batch & $\begin{array}{c}\text { Extracted } \\
\text { residue obtained } \\
\text { from } 10 \mathrm{ml} \text { of } \\
\text { market } \\
\text { preparation (mg) }\end{array}$ & $\begin{array}{c}\text { Vasicine } \\
\text { concentration in } 150 \\
\mu \mathrm{g} / \mathrm{ml} \text { of extracted } \\
\text { residue solution } \\
(\mu \mathrm{g} / \mathrm{ml})\end{array}$ & $\begin{array}{c}\text { Vasicine } \\
\text { content in } 10 \\
\text { ml of market } \\
\text { preparation } \\
\text { (mg) }\end{array}$ & $\begin{array}{l}\text { Vasicine content } \\
\text { in } 100 \mathrm{ml} \text { of } \\
\text { market } \\
\text { preparation } \\
\text { (g) }\end{array}$ & $\begin{array}{c}\text { Average content } \\
\text { (g) } \\
\pm \\
\text { S.D. }\end{array}$ \\
\hline \multirow[t]{3}{*}{ A } & 1 & 950.18 & 22.655 & 143.509 & 1.435 & \multirow{3}{*}{$\begin{array}{c}1.502 \\
\pm \\
0.064\end{array}$} \\
\hline & 2 & 947.72 & 24.732 & 156.260 & 1.563 & \\
\hline & 3 & 958.56 & 23.615 & 150.909 & 1.509 & \\
\hline \multirow[t]{3}{*}{ B } & 1 & 768.94 & 29.197 & 149.672 & 1.497 & \multirow{3}{*}{$\begin{array}{c}1.590 \\
\pm \\
0.081\end{array}$} \\
\hline & 2 & 780.15 & 31.652 & 164.622 & 1.646 & \\
\hline & 3 & 778.75 & 31.322 & 162.613 & 1.626 & \\
\hline \multirow[t]{3}{*}{ C } & 1 & 783.27 & 32.370 & 169.030 & 1.690 & \multirow{3}{*}{$\begin{array}{c}1.761 \\
\pm \\
0.061\end{array}$} \\
\hline & 2 & 790.33 & 33.961 & 178.936 & 1.789 & \\
\hline & 3 & 798.72 & 33.839 & 180.186 & 1.802 & \\
\hline \multirow[t]{3}{*}{$\mathrm{D}$} & 1 & 872.67 & 28.874 & 167.983 & 1.680 & \multirow{3}{*}{$\begin{array}{c}1.627 \\
\pm \\
0.082\end{array}$} \\
\hline & 2 & 886.38 & 28.253 & 166.953 & 1.670 & \\
\hline & 3 & 878.41 & 26.179 & 153.306 & 1.533 & \\
\hline
\end{tabular}

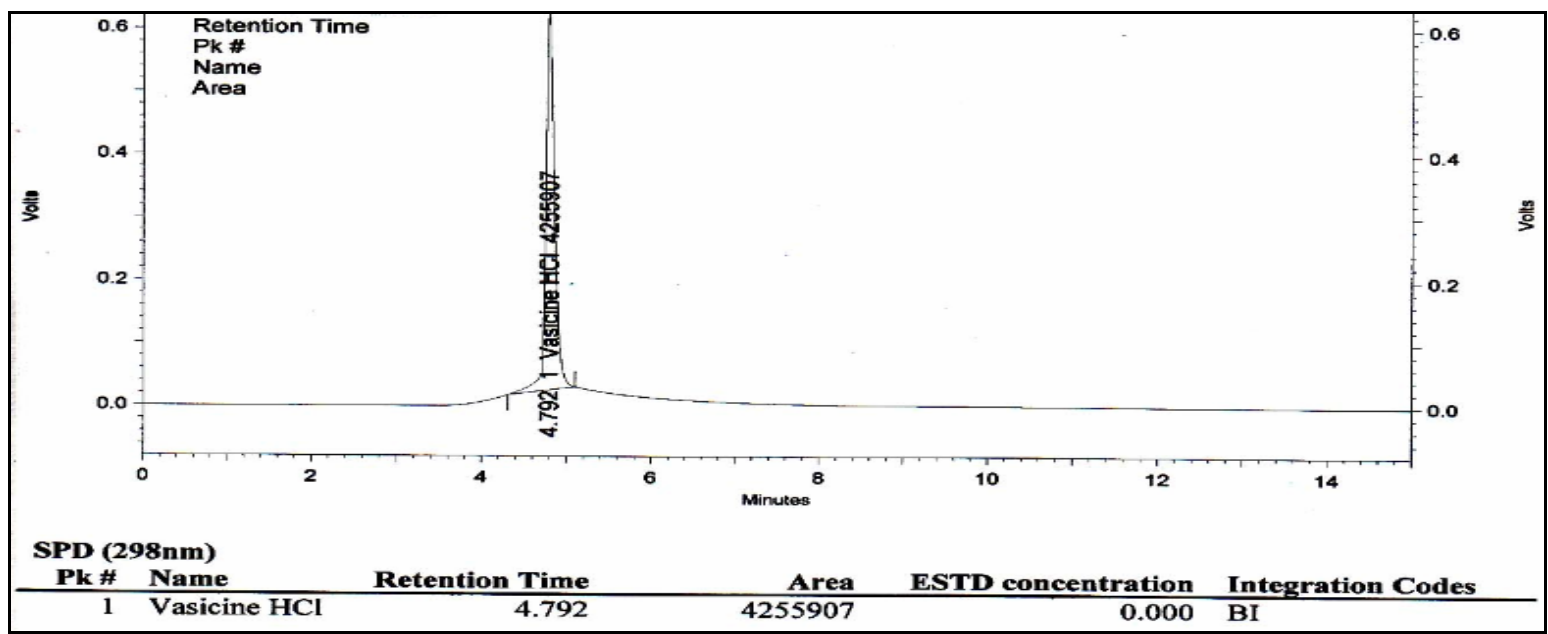

Figure 1. Chromatogram for reference standard of vasicine observed by RP-HPLC. 


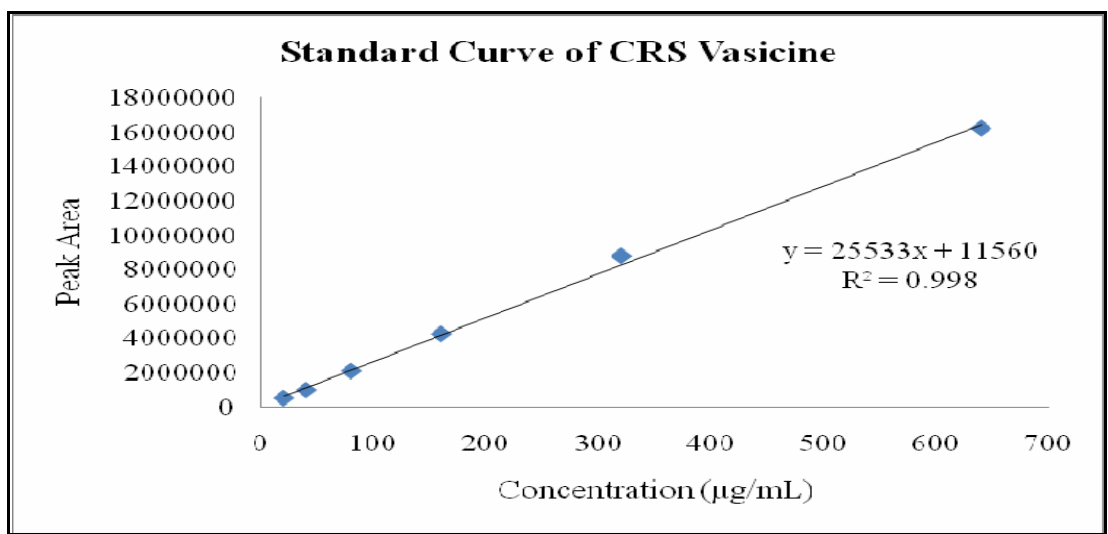

Figure 2. Calibration curve for reference standard of vasicine.
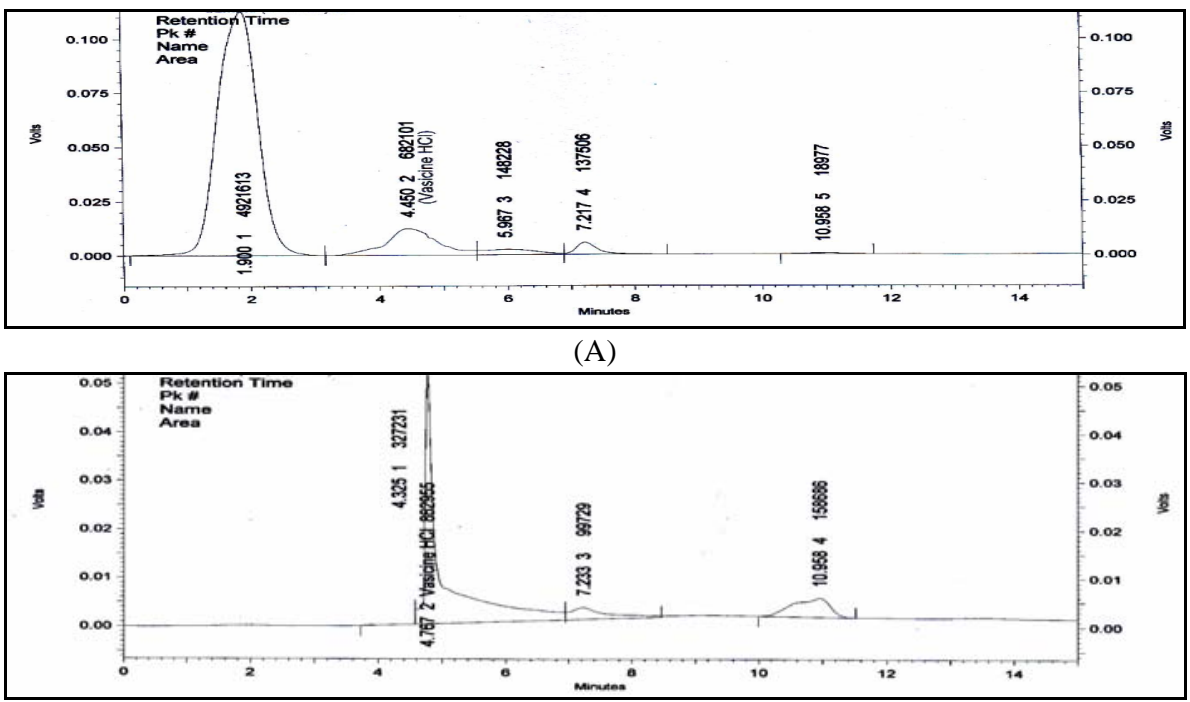

(B)

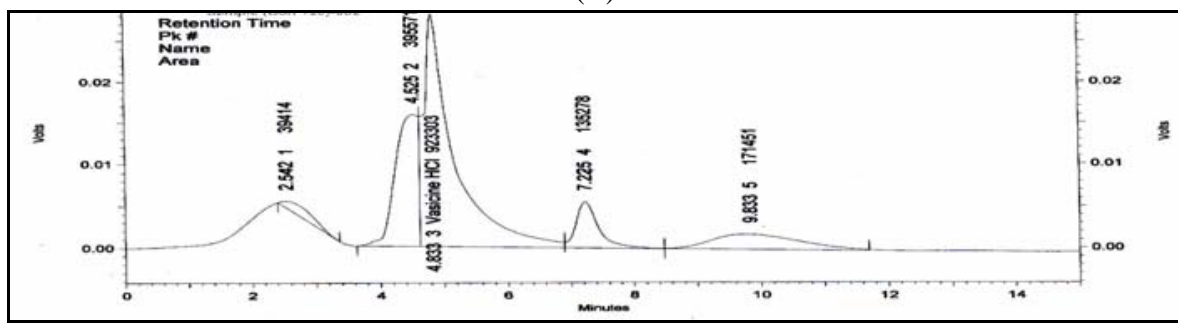

(C)

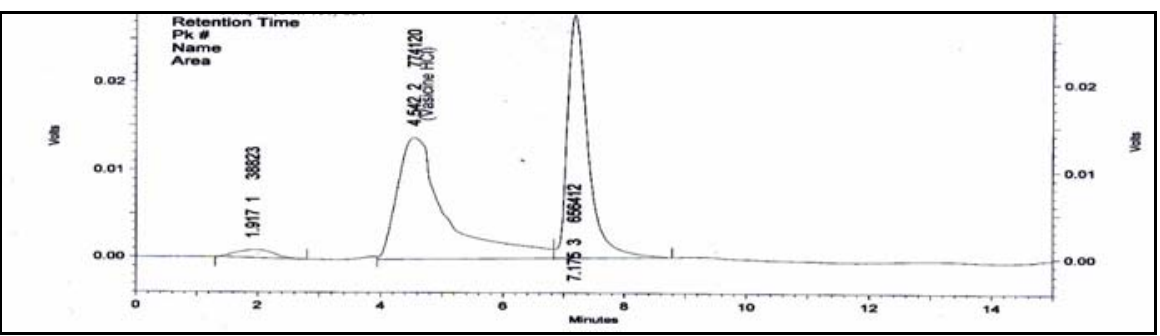

(D)

Figure 3. Chromatograms of A. vasica market preparations (sample A-D) obtained during RP-HPLC analyses. 


\section{CONCLUSION}

Recently, most of the herbal and traditional manufacturers have been marketing A. vasica preparations for its potential bronchodilatory activity but due to lack of proper instrumentations and knowledge, manufacturers cannot maintain the desired quality requirements of the preparations. The described method will be supportive to herbal and traditional manufactures for producing A. vasica preparations maintaining quality requirements imposed by the regulatory authorities.

\section{AKNOWLEDGEMENTS}

The authors are thankful to the authority of Square Herbal and Neutraceuticals Limited, Pabna, Bangladesh for providing reference standard vasicine. The authors are also indebted to $\mathrm{Mr}$. Subrata Bhadra, Assistant Professor, Department of Pharmaceutical Technology, Faculty of Pharmacy, University of Dhaka, Dhaka-1000, Bangladesh for his cordial support during the study.

\section{REFERENCES}

1. Awang, D.V.C. 1997. Quality control and good manufacturing practices: Safety and efficacy of commercial herbals. Food Drug Law Inst. 52, 341-344.

2. Ravishankar, B. and Shukla, V.J. 2007. Indian systems of medicine: A brief profile. Afr. J. Trad. Cam. 4, 319-337.

3. Farnsworth, N.R., Akerele, O. and Bingel, A.S. 1985. Medicinal plants in therapy. Bull. World Health Org. 63, 965-981.

4. World Health Organization, 1998. Essential medicines and health products information portal: Guidelines for the appropriate uses of herbal medicines- A World Health Organization Resource, Regional Office for the Western Pacific, Manila.
5. Nadkarni, K.M. 1976. Indian Materia Medica, Popular Prakashan, Bombay, India, Chapter 1, pp. 40-41.

6. Atal, C.K. 1980. Chemistry and pharmacology of vasicine: A new oxytocic and abortifacient, New Delhi Press, New Delhi, India, Chapter 5, pp. 58-59.

7. Gupta, O.P., Sharma, M.L. and Ghatak, B.J.R. 1977. Pharmacological investigations of vasicine and vasicinone: The alkaloids of Adhatoda vasica. Indian J. Med. Res. 66, 680-691.

8. Rachana, Sujata, B., Mamta, P., Priyanka, K.M. and Sonam, S. 2011. Review \& future perspectives of using vasicine, and related compounds. Indo-Global J. Pharmaceut. Sci. 1, 85-98.

9. Nikam, P.H., Kareparamban, J., Jadhav, A. and Kadam, V. 2012. Future trends in standardization of herbal drugs. $J$. Appl. Pharmaceut. Sci. 6, 38-44.

10. Kunle, Folashade, O., Omoregie, E.H. and Ochogu, A.P. 2012. Standardization of herbal medicines: A review. Int. J. Biodiver. Conserv. 4, 101-112.

11. Dixit, V.K. and Yadav, N.P. 2008. Recent approaches in herbal drugs standardization. Integr. Biol. 2, 195-203.

12. Jianga, Y., David, B., Tu, P. and Barbin, Y. 2010. Recent analytical approaches in quality control of traditional Chinese medicines- A review. Anal. Chim. Acta. 657, 9-18.

13. Sajeeb, B.K., Kumar, U., Rouf, A.S.S., Uddin, M.A. and Bachar, S.C. 2015. Evaluation of Justicia adhatoda L. syn. Adhatoda vasica Nees extract by major metabolite analysis. Indian J. Trad. Knowl. 14, 637-642.

14. Ravishankara, M.N., Shrivastava, N., Mahendru, N., Padh, H. and Rajani, M. 2001. Spectrophotometric method for the estimation of alkaloids from Cinchona officinalis's stems, bark and its formulations. Indian J. Pharm. Sci. 63, 76-78. 